\title{
Carbon Dioxide Capture from Flue Gas Using a Potassium-Based Sorbent in a Circulating-Turbulent Fluidized Bed
}

\author{
Pilaiwan Chaiwang ${ }^{1}$, Benjapon Chalermsinsuwan ${ }^{1,2}$, and Pornpote Piumsomboon ${ }^{1,2, *}$ \\ 1 Fuels Research Center, Department of Chemical Technology, Faculty of Science, Chulalongkorn \\ University, 254 Phayathai Road, Patumwan, Bangkok 10330, Thailand \\ 2 Center of Excellence on Petrochemical and Materials Technology, Chulalongkorn University, 254, \\ Phayathai Road, Patumwan, Bangkok 10330, Thailand \\ *E-mail: pornpote.p@chula.ac.th
}

\begin{abstract}
This research aimed to study the carbon dioxide $\left(\mathrm{CO}_{2}\right)$ capture process using a potassium-based solid sorbent in a circulating fluidized bed riser (CFBR). The solid sorbent in this study was potassium carbonate on gamma alumina supporter $\left(\mathrm{K}_{2} \mathrm{CO}_{3} / \gamma-\mathrm{Al}_{2} \mathrm{O}_{3}\right)$. The hydrodynamics under a circulating-turbulent fluidized bed (C-TFB) regime occurred when the gas velocity was $1.00 \mathrm{~m} / \mathrm{s}$ and could promote a solid sorbent distribution, with transition and transport velocities of 0.82 and $2.22 \mathrm{~m} / \mathrm{s}$, respectively, giving a uniform solid volume fraction distribution of 0.15 along the CFBR for the $\mathrm{CO}_{2}$ capture process. The study started with finding the operating condition in the riser so that the particle flowed in the reactor in the C-TFB regime. In addition, the kinetic of the adsorption under C-TFB flow regime in the riser was studied and the kinetic parameters corresponding to C-TFB flow regime were determined using deactivation kinetic model.
\end{abstract}

Keywords: Adsorption kinetics, $\mathrm{CO}_{2}$ capture, fluidization, hydrodynamics, potassium based solid sorbent.

ENGINEERING JOURNAL Volume 23 Issue 5

Received 7 March 2019

Accepted 11 June 2019

Published 30 September 2019

Online at http://www.engj.org/

DOI:10.4186/ej.2019.23.5.13 


\section{Introduction}

According to EIA Energy Outlook in 2017, the long-term projection worldwide energy market suggests that the trend of world energy consumption further increase until 2040. Especially, Non-OECD (Organization for Economic Cooperation and Development) countries tends to require an excessive amount of resource for energy supplies more than OECD countries. Due to the economic growth and rise of population, their prediction will be increased above the reference case. Energy supplies probably come from various types such as fossil fuels, including coals, natural gas, oil and alternative fuels. However, coals will continue to be used as a conventional energy supplies in power plants for generating electricity and heating in industries for the near future. It is clear that the major current problem of selecting coal as a primary energy supply is the issue of greenhouse gas emissions. Burning coal and then releasing carbon dioxide $\left(\mathrm{CO}_{2}\right)$ as part of the exhaust gas into the atmosphere leads to the occurrence of global warming, and so this severe problem is of concern for the construction of new and the operation of existing power plants. Nowadays, the power plants are concerned with this severe problem, addressed by highly efficient energy conversion improvement plan and eliminated $\mathrm{CO}_{2}$ from the waste gas of burning.

Several methods have been invented for suitable approaches which can be corresponded with $\mathrm{CO}_{2}$ capture process. Carbon dioxide storage and sequestration (CSS) process are widely used depending on power plant process operations, consisting of pre-combustion capture, post-combustion capture, oxy-combustion and chemical looping combustion. Post-combustion processes have been considered as the most practical method to remove $\mathrm{CO}_{2}$ from the flue gas of existing power plants. Since there is no radical change and can operate with an uncomplicated system. Flue gas from a coal-fired power plant contains $10-15 \% \mathrm{CO}_{2}[1]$ and mostly $\mathrm{N}_{2}$ through the clean-up process including an electrostatic precipitator (ESP), a flue gas desulfurization (FGD). One such promising method is to use a solid sorbent loaded with an alkaline metal as the adsorbent. Solid sorbents can overcome some of the limitations of the more conventional liquid aminebased absorption. Solid support materials loaded with active alkali-metal components such as Na- and Kbased have become a highly efficient method for capturing $\mathrm{CO}_{2}$ due to their high $\mathrm{CO}_{2}$ capture capacity, low cost and low energy requirement for capturing and releasing the $\mathrm{CO}_{2}[2-6]$. The mechanism of $\mathrm{CO}_{2}$ capture for these porous materials such as activated carbon, $\mathrm{TiO}_{2}, \mathrm{MgO}$, zeolite and activated alumina adsorbents [7, 8] can be described in Eq. (1) as follows:

$$
\mathrm{CO}_{2}+\text { surface } \Leftrightarrow\left(\mathrm{CO}_{2}\right) \cdot(\text { surface })
$$

Therefore, this study will be focused on the removal of $\mathrm{CO}_{2}$ from flue gas by using a potassium-based solid sorbent in a circulating fluidized bed riser (CFBR). A novel fluidization regime, called a circulating-turbulent fluidization (C-TFB), was firstly employed to capture the $\mathrm{CO}_{2}$ and the adsorption kinetics in this regime was also determined.

\section{Theoretical Background}

\subsection{Solid Sorbent}

Several methods for removing $\mathrm{CO}_{2}$ exhaust gas streams from power plants have been investigated for a decade such as solvent absorption, cryogenic separation, membrane separation and molecular sieve. The medium which can be used to separate $\mathrm{CO}_{2}$ gas are mainly liquid and solid. The solid support materials with alkali-metal active component loading have become a highly efficient method for capturing $\mathrm{CO}_{2}$ due to high $\mathrm{CO}_{2}$ capture capacity, low cost and low energy requirement for capturing and releasing $\mathrm{CO}_{2}$, which called solid sorbent method. Many researchers have been investigated a solid sorbents containing alkali metal $\left(\mathrm{Na}_{2} \mathrm{CO}_{3}\right.$ and $\left.\mathrm{K}_{2} \mathrm{CO}_{3}\right)[2,4,5,7-13]$ and a solid sorbents containing alkali earth metal $(\mathrm{MgO}$ and $\mathrm{CaO})[14$, 15] for carbon dioxide sorption. However, the carbonation reaction rate of $\mathrm{Na}_{2} \mathrm{CO}_{3}$ was rather slow [16]. The attrition resistance (AI) and the corrected attrition index (CAI) of $\mathrm{K}_{2} \mathrm{CO}_{3}$ were higher than those of $\mathrm{Na}_{2} \mathrm{CO}_{3}$ sorbent $[5,9,17]$. For solid sorbent regeneration, the alkali metal required low regeneration temperature comparing with the alkali earth metal. Thus, alkali metal seems to be favorable as a solid sorbent.

Types of solid sorbent support, including activated carbon, $\mathrm{TiO}_{2}, \mathrm{MgO}, \mathrm{SiO}_{2}$ and activated alumina $\left(\mathrm{Al}_{2} \mathrm{O}_{3}\right)$, also play a dominant role for $\mathrm{CO}_{2}$ adsorption-regeneration behaviors [7, 8]. Furthermore, the characteristics of various supporting materials, after loaded by alkali-metal and adsorbed with $\mathrm{CO}_{2}$ gas, were 
distinguished [18]. In the fluidization process, the solid particles move in both upward and downward directions in the reactor perpetually due to the dynamics of gas velocity. The contacting occasion between particle-particle and gas-particle are increased which leads to solid particle attritions. Therefore, the mechanical strength of solid support becomes one of the important factors to be considered as solid sorbent property. For this reason, this study will be focusing on gamma-alumina solid support since this support has low attrition index characteristic and high surface area.

\subsection{Circulating-Turbulent Fluidized Bed (C-TFB)}

A novel circulating-turbulent fluidized bed regime (C-TFB) was proposed by Zhu and Zhu [19, 20]. This CTFB regime combined the advantages of fast fluidization regime and turbulent fluidization regime together. The C-TFB flow behavior showed its inherent characteristics which was different from those in conventional circulating fluidized bed (CFB), turbulent fluidization (TFB) and high density CFB (HDCFB) reactors [21]. Subsequently, the flow pattern characteristics of turbulent fluidization, circulating-turbulent fluidization and fast fluidization flow regimes were evaluated by experimental and computational fluid dynamics simulations (CFDS) approaches and revealed a uniform solid volume fraction (SVF) across the axial system direction in the C-TFB flow behavior [22]. This dense and uniform flow pattern will have an advantage on the physical and chemical processes including the enhancement of the mixing between gas-solid particles and the improvement of high heat and mass transfers between the phases at the top of the riser.

The axial differential pressure profiles in C-TFB showed nearly uniform behaviors. The differential pressures profiles increased with increasing solid mass flux, $G_{s}$, and decreasing superficial gas velocities, $U_{g}$. In addition, it was found that the dense gas-solid particle suspension has been achieved along the whole system column.

\subsection{Kinetic Models}

The investigation of chemical kinetics is needed to provide better understanding of the $\mathrm{CO}_{2}$ sorption process. The potassium carbonate (B) solid sorbent reacted with $\mathrm{CO}_{2}(\mathrm{~A})$ and moisture (W) to form potassium bicarbonate as a product in the following equation:

$$
\mathrm{K}_{2} \mathrm{CO}_{3}(s)+\mathrm{CO}_{2}(g)+\mathrm{H}_{2} \mathrm{O}(g) \leftrightarrow 2 \mathrm{KHCO}_{3}(s)
$$

Basically, the explanation of mass transfer and chemical reaction can be clarified in the chemical kinetic term by mathematics. Developing the gas-solid particle reaction by using the mathematical models in order to predict the reaction conversion is necessary for the optimization of the process. Various mathematical models including the shrinking-core, homogeneous, phenomenological and simplified deactivation models are proposed. For the shrinking-core model, the reaction occurs at the external region of the solid particle, then moves toward the center containing the unreacted core. The ash was formed on the surface of reacted particles [23].

$$
-\frac{d}{d t}\left(\frac{4 \pi r^{3} \rho_{B}}{3 M_{B}}\right)=4 \pi r^{2} k_{1} C_{A}
$$

where $k_{1}=k_{S} C_{W}$ and $\mathrm{k}_{1}$ is constant if $\mathrm{C}_{\mathrm{w}}>\mathrm{C}_{\mathrm{A}}$ ( $\mathrm{k}_{\mathrm{S}}$ is a rate constant in shrinking-core model, $\mathrm{r}$ is radius of spherical particle, $\rho_{\mathrm{B}}$ and $\mathrm{M}_{\mathrm{B}}$ are density and molecular weight of $\mathrm{CO}_{2}$, respectively)

The gas-solid reaction takes place throughout the porous solid sorbent and the diffusion rate occurs rapidly in homogeneous model. Degrees of reaction may require due to the existed diffusional gradients.

$$
-\frac{d C_{B}}{d t}=k_{2} C_{A} C_{B}
$$

where $k_{2}=k_{H} C_{w}$ ( $\mathrm{k}_{\mathrm{H}}$ is a rate constant in homogeneous model, $\mathrm{C}_{\mathrm{A}}, \mathrm{C}_{\mathrm{B}}$ and $\mathrm{C}_{\mathrm{W}}$ are the concentration of $\mathrm{K}_{2} \mathrm{CO}_{3}, \mathrm{CO}_{2}$, and initial $\mathrm{H}_{2} \mathrm{O}$, respectively). 
The phenomenological kinetic model has been developed from the conversion of solid sorbent via the time-dependent rate. Generally, the extended conversion of reactant, $\alpha$, is practically used since the concentration of solid cannot be obtained numerically. The governing kinetic equation can be described as a function of temperature-dependent and the extended conversion of reactant proposed by Lee, et al. [24], as follows:

$$
r=k_{3}(T) f(\alpha) f\left(\mathrm{CO}_{2}\right)
$$

where $\mathrm{k}_{3}$ is a rate constant of the phenomenological model, $f(\alpha)$ is a rate-affecting term as a function of conversion and $f\left(\mathrm{CO}_{2}\right)$ is a rate dependency as a function of $\mathrm{CO}_{2}$ mole fraction in the bulk phase.

Among these models, the deactivation model which presented by Zhao, et al. [6] had been used to describe behavior of solid sorbent during $\mathrm{CO}_{2}$ sorption. Based on diffusion resistance which occurred by a product layer deposited over the solid pore volume or solid surface, the phenomenon showed that the rate of chemical reaction was decreasing when the reaction time increased. The solid sorbent activity, $a$, at any time then changed with solid particle textural changes.

The deactivation model has some additional conditions to be assumed: the operation condition of the reaction is under isothermal and the water vapor content is constant. With the above assumptions, the pseudo-steady state species conservation equation without axial dispersion is expressed in Eqs. (6) and (7) as follows:

$$
-Q_{0} \frac{d C}{d W}-k_{0} a C=0
$$

where $a$ is the activity of the sorbent, $\mathrm{W}$ is the weight of sorbent, $\mathrm{C}$ is the outlet concentration of $\mathrm{CO}_{2}, \mathrm{Q}_{0}$ is the volumetric flow rate and $\mathrm{k}_{0}$ is the initial sorption rate constant:

$$
\int_{C_{0}}^{C} \frac{d C}{C}=-\left(\frac{k_{0} a}{Q_{0}}\right) \int_{0}^{W} d W \Rightarrow \ln \left(\frac{C}{C_{0}}\right)=-\left(\frac{k_{0} a}{Q_{0}}\right) W
$$

where $C_{0}$ is the inlet concentration of $\mathrm{CO}_{2}$. For the deactivation effect, the calculation of $\mathrm{K}_{2} \mathrm{CO}_{3} / \mathrm{Al}_{2} \mathrm{O}_{3}$ solid sorbent activity will depend on the hypothesis. If the first-order with respect to the solid active site and zero-order with respect to the concentration of $\mathrm{CO}_{2}$ are assumed $(\mathrm{m}=1, \mathrm{n}=0)$, the solid sorbent activity can then be described by the following in Eq. (8):

$$
\frac{-d a}{d t}=k_{d} C^{m} a^{n} \quad \Rightarrow a=a_{0} \exp \left(-k_{d} t\right)(m=0, n=1)
$$

where $t$ is the time, $k_{d}$ is the deactivation rate constant and $a_{0}$ is the initial activity of the solid sorbent. Substituting Eq. (8) into Eq. (7) with the initial activity of the solid sorbent as the unity, Eq. (9) can be expressed in the general form below $(\mathrm{m}=1, \mathrm{n}=1)$.

$$
\frac{C}{C_{0}}=\exp \left[1-\frac{\exp \left(\frac{k_{0} W}{Q_{0}}\right)\left(1-\exp \left(-k_{d} t\right)\right)}{\left(1-\exp \left(-k_{d} t\right)\right)}\right] \exp \left(-k_{d} t\right)
$$




\section{Experimental Setup}

\subsection{Apparatus and Procedure}

\subsubsection{Hydrodynamics study}

The apparatus of circulating fluidized bed systems was further explored from the investigation of $\mathrm{CO}_{2}$ capture on various fluidization regimes by Jaiboon et al. [25]. This study consisted of four main parts including a riser, a downcomer, a cyclone and a solid storage sector for solid recirculation instead of semi-circulating fluidized bed as shown in Fig. 1. Make-up air was added at the position below the solid storage for moving solid sorbent through the riser. The riser and downcomer parts had the total height of $0.70 \mathrm{~m}$ and $0.50 \mathrm{~m}$, respectively, and inside diameter of $0.025 \mathrm{~m}$. Solid particles were contacted with inlet gas at the bottom of the riser at various velocities to form the desired flow patterns/regimes. After reaching to the top of the cyclone, solid particles transported to the downcomer then returned to the riser as a continuous process. To investigate C-TFB flow patterns/regimes, the pressure drop measurements between pressure sensors along the riser height were assembled. The measurement ports which consist of eight pressure sensors were mounted along the height at every $0.10 \mathrm{~m}$ upwards from the porous plate distributor with the $27 \%$ open area from the bottom for monitoring pressure instantaneously. At the connecting position, 400 mesh sieve was used to avoid small particle blockage and protect sensor apparatus. The computation of the pressure drop profiles was carried out by obtaining the data from MultiLab data logger version 4.0. It collected and recorded pressure data then exported the data as MS Excel file. Then the data were used to calculate the axial solid volume fraction profile.

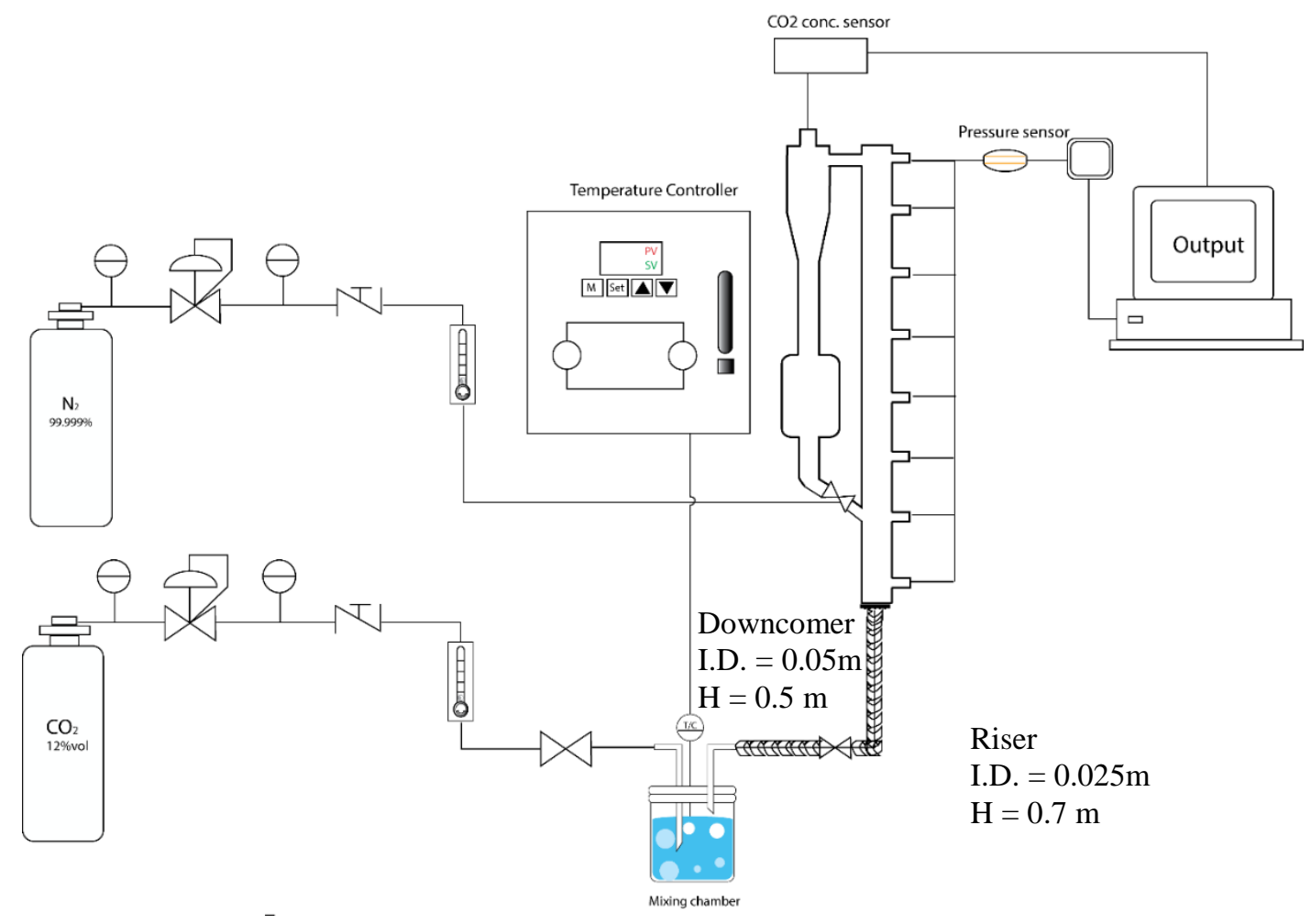

Fig. 1. Schematic diagram of a lab-scale circulating fluidized bed unit in this research.

A cyclone was installed at the exit of the riser to remove fine particles out from the top of the cyclone. Coarse particles or particulate solids would contact the cyclone wall, then fell down to the downcomer which attached to the storage section. This section was used to store solid particles for a certain amount before being delivered into the riser. Solid particles then continuously moved into the riser through the transfer line. Make-up air was also added to the transfer line to support and carry over solid particles in the downcomer to the riser. Inlet gas velocity could be supplied at the bottom of the riser through a distributor, resulting in the uniform flow. The superficial gas velocity was measured by a rotameter. In this study, gas velocities 
became an influencing parameter because when the gas velocity increased, the flow patterns/regimes changed.

\subsubsection{Sorbent preparation}

An aqueous solution consists of 5.0 grams of activated-alumina $\left(\gamma-\mathrm{Al}_{2} \mathrm{O}_{3}\right)$ as a supporting material added into 5.0 grams of anhydrous potassium carbonate $\left(\mathrm{K}_{2} \mathrm{CO}_{3}\right)$, purity $99.99 \%$, then dissolved in $15 \mathrm{ml}$ deionized water. At room temperature, the precursors were mixed to become a solution in a stirrer for $24 \mathrm{hrs}$. After stirring, the solution was filtered and dried at $105^{\circ} \mathrm{C}$ in a vacuum oven. The dried solid sorbent was grinded and sieved to collect the solid particle in the desired range $(100 \mu \mathrm{m})$. After collected the desired size, the sample were calcined for $4 \mathrm{~h}$ at $300^{\circ} \mathrm{C}$ with ramping rate of $3^{\circ} \mathrm{C} / \mathrm{min}$. The outline of approaches used for preparing $\mathrm{K}_{2} \mathrm{CO}_{3} / \gamma-\mathrm{Al}_{2} \mathrm{O}_{3}$ solid sorbent process is shown in Fig. 2. The actual amount of composing elements of alkaline metal impregnated on solid sorbent each sample was measured by using an X-ray fluorescence analysis (XRF). The properties of prepared solid sorbent in this study are illustrated in Table 1.

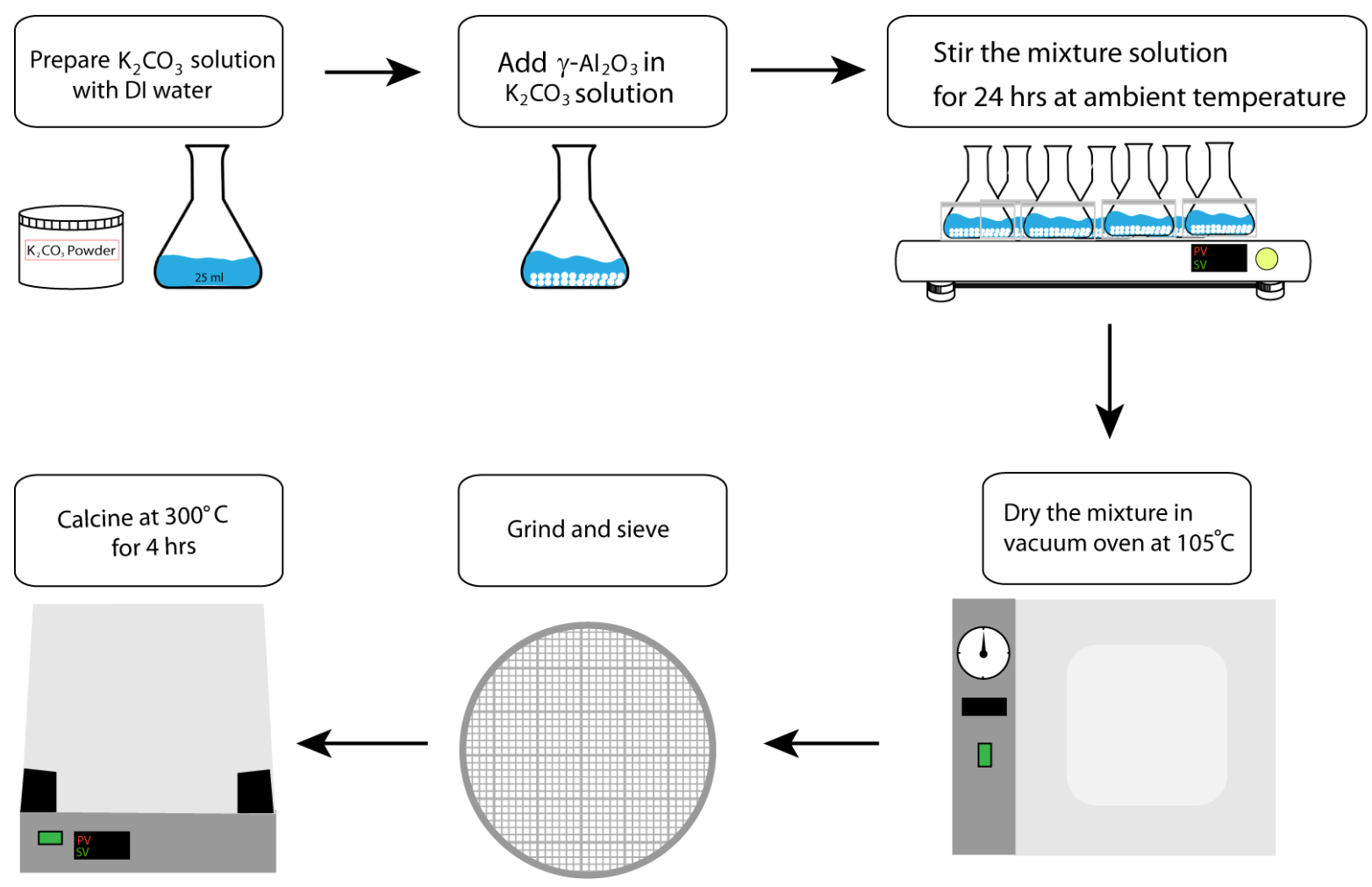

Fig. 2. The outline of the procedure used for preparing $\mathrm{K}_{2} \mathrm{CO}_{3} / \mathrm{Al}_{2} \mathrm{O}_{3}$ solid sorbent process.

Table 1. Characteristics of prepared $\mathrm{K}_{2} \mathrm{CO}_{3} / \mathrm{Al}_{2} \mathrm{O}_{3}$ solid sorbent in this research.

\begin{tabular}{ll} 
Sorbent Properties & Value \\
& \\
\hline $\mathrm{K}_{2} \mathrm{CO}_{3} / \mathrm{Al}_{2} \mathrm{O}_{3} \mathrm{BET}$ surface area $\left(\mathrm{m}^{2} / \mathrm{g}\right)$ & 99.51 \\
Pure $\mathrm{Al}_{2} \mathrm{O}_{3}$ BET surface area $\left(\mathrm{m}^{2} / \mathrm{g}\right)$ & 117.94 \\
$\mathrm{~K}_{2} \mathrm{CO}_{3} / \mathrm{Al}_{2} \mathrm{O}_{3}$ Pore volume $\left(\mathrm{cm}^{3} / \mathrm{g}\right)$ & 0.17 \\
Pure $\mathrm{Al}_{2} \mathrm{O}_{3}$ Pore volume $\left(\mathrm{cm}^{3} / \mathrm{g}\right)$ & 0.21 \\
Particle size distribution $(\mu \mathrm{m})$ & $63-200$ \\
Actual weight of $\mathrm{K}_{2} \mathrm{CO}_{3}$ impregnated on $\gamma-\mathrm{Al}_{2} \mathrm{O}_{3}(\%$ wt $)$ & 10.2 \\
$\mathrm{~K}_{2} \mathrm{CO}_{3} / \mathrm{Al}_{2} \mathrm{O}_{3}$ diameter $\left(\mathrm{d}_{\mathrm{p}}, \mu \mathrm{m}\right)$ & 150 \\
\hline
\end{tabular}

\subsection{3. $\mathrm{CO}_{2}$ capture}


For $\mathrm{CO}_{2}$ capture capacity, moistur e had become an important factor for alkali-metal solid sorbent for both pre-treatment and adsorption processes. With sufficient amount of water content and time, an active species was found in potassium-based solid sorbent after water pre-treatment which could directly increase the $\mathrm{CO}_{2}$ capture capacity [26]. The water vapor content was calculated by the steam generation temperature. Assuming that the mixed gas stream from a gas bubbler remained saturated with water vapor which could be estimated by the relative humidity. The transfer tubes were wrapped up with heating tapes to prevent water vapor condensation. An unadsorbed portion of the feed gas stream which contained $\mathrm{CO}_{2}$ and water vapor was passed through a filter at the exit of the riser. Then mixed gas at the outlet was collected and measured the amount of $\mathrm{CO}_{2}$ concentration by using $\mathrm{CO}_{2}$ sensor $\left(\mathrm{CO}_{2}\right.$ meter Co. Ltd.). Table 2 shows experimental conditions of $\mathrm{CO}_{2}$ adsorption.

In this study, the dry basis feed gas, composed of $12 \% \mathrm{CO}_{2}$ with $\mathrm{N}_{2}$ balance, was used as simulated flue gas. The reaction temperature was $60^{\circ} \mathrm{C}$ in the presence of $\mathrm{CO}_{2}$ and $\mathrm{H}_{2} \mathrm{O}$ streams. Water vapor was produced in a gas bubbler where the feed gas was fed into via a tube submerging the water level to moisten it. The moisten gas left the bubbler via another tube probing above the water level and entered to the riser. Then, $\mathrm{CO}_{2}$ adsorption was taken place in the riser and the data of $\mathrm{CO}_{2}$ concentration at the riser outlet were collected by the sensor. Breakthrough curves were represented in the term of $\mathrm{CO}_{2}$ concentration at the riser outlet with respect to time. The area under these curves then could be used for calculating the $\mathrm{CO}_{2}$ capture capacity. The expression of the capture capacity was defined as the amount of the adsorbed $\mathrm{CO}_{2}$ per $1 \mathrm{~g}$ of $\mathrm{K}_{2} \mathrm{CO}_{3}$. An adsorption reaction between potassium carbonate sorbent, water vapor and $\mathrm{CO}_{2}$ can be depicted in Eq. (2)

Table 2. Experimental conditions of an adsorption temperature effect on $\mathrm{CO}_{2}$ adsorption.

\begin{tabular}{lc}
\hline Conditions & Value \\
\hline Adsorption temperature $\left({ }^{\circ} \mathrm{C}\right)$ & 60 \\
Pressure $(\mathrm{atm})$ & 1 \\
Flow pattern regime & Circulating-turbulent fluidized bed \\
Gas velocity $(\mathrm{m} / \mathrm{s})$ & 1.0 \\
Solid loading $(\mathrm{kg})$ & 0.5 \\
Gas composition $(\mathrm{vol} \%)$ & $12 \% \mathrm{CO}_{2}$ dry basis with $\mathrm{H}_{2} \mathrm{O} 18.5 \%, \mathrm{~N}_{2}$ balance \\
\hline
\end{tabular}

\section{Results and Discussion}

\subsection{Investigation of Circulating Turbulent Fluidized-Bed (C-TFB) Regime}

According to Zhu and Zhu literature [20], the hydrodynamic characteristics representing circulating-turbulent fluidized bed or C-TFB regime will be investigated in this study. The literature result was claimed that C-TFB regime combined the advantages of turbulent fluidized bed and fast fluidization fluidized bed which increased a high level of gas-solid contacts as well as high heat and mass transfers. Hence, to distinguish C-TFB flow characteristics, two types of velocities consisted of transition velocity $\left(\mathrm{u}_{c}\right)$ and transport velocity $\left(\mathrm{u}_{\mathrm{tr}}\right)$ would be measured before the further study of $\mathrm{CO}_{2}$ capture. Transition velocity $\left(\mathrm{u}_{c}\right)$ indicates the transition state from bubbling to turbulent fluidization while the transport velocity indicates that between turbulent and fast fluidization regime, respectively.

\subsubsection{Transition velocity (UC)}

Turbulent fluidization regime is considered as one of a high-velocity fluidization regime. As increasing the superficial gas velocity $\left(\mathrm{u}_{\mathrm{g}}\right)$ flow through a bed above the minimum bubbling velocity $\left(\mathrm{u}_{\mathrm{mb}}\right)$, the bed of solid particles is firstly moving. If the gas velocity is still increased further, the terminal velocity of solid is exceeded. Then, the bubbling bed expansion changes the flow pattern to be in turbulent fluidization. In the turbulent fluidization regime, the bed expansion is increased as a result of the predominance of bubble break-up condition [27]. The gas velocity carried the amount of solid particles out of the expanded bed into the 
freeboard region. Thus, the turbulent fluidization regime can divide into two main regions, consisting of dense phase in the lower region and dilute dispersed phase in the upper region [28].

Transition state from bubbling/slugging to turbulent fluidization can be distinguished by two transition criteria. The first criterion is transition velocity, $\mathrm{u}_{\mathrm{c}}$, which can be defined as the onset of the turbulent flow regime. In order to investigate $\mathrm{u}_{C}$, pressure probe was installed at an axial position of $0.10 \mathrm{~m}$ above the distributor. As the superficial gas velocity was increasing, the bubbles or slugs in the bed of particles also increased. The bubble diameter expanded and reached its maximum value which gave the largest standard deviation of the pressure fluctuation. After that, the large bubbles in the bed were broken-up into smaller bubbles.

The standard deviation of the pressure fluctuation is shown in Fig. 3. When the gas velocity was increased, the standard deviation of pressure fluctuation in bubbling flow regime increased rapidly due to the coalescence of small bubbles into large bubbles/slugs. The transition velocity was corresponding to the gas velocity which this standard deviation reached its maximum. Therefore, $\mathrm{u}_{\mathrm{c}}$ in this study was found to be 0.82 $\mathrm{m} / \mathrm{s}$. Above the $u_{c}$, the standard deviation decreased gradually with the increasing of gas velocity due to the fast break-up of large bubbles into small bubbles._The comparison of obtained transition velocity between literature correlations and this study value were consistent as can be seen in Table 3 .

The other criterion used to identify transition state into the turbulent regime is critical velocity, $\mathrm{u}_{\mathrm{k}}$. When increasing the gas velocity, the large bubbles in the bed started to erupt into smaller bubbles at which the standard deviation of the pressure fluctuation became less and stabilize [29].

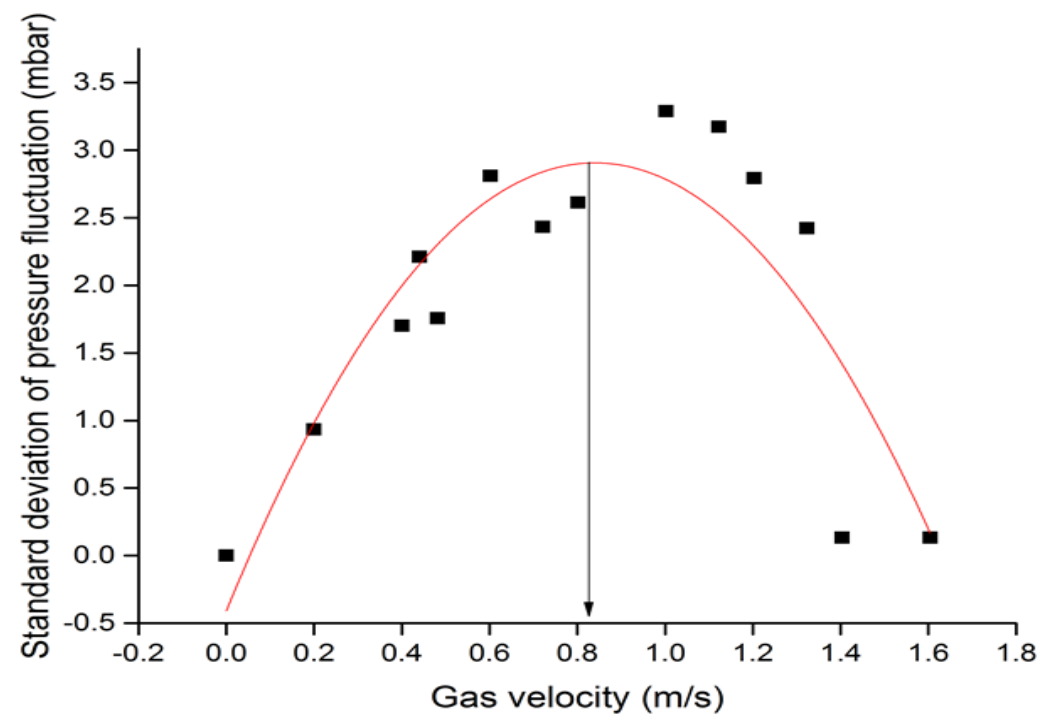

Fig. 3. Transition velocity by standard deviation of pressure fluctuation-gas velocity curve, position of the probe: $0.20 \mathrm{~m}$.

Table 3. Comparison between transition velocity from correlations and velocity determined in this research.

\begin{tabular}{lll}
\hline References & Correlations of $\mathbf{u}_{\mathbf{c}}$ & $\mathbf{u}_{\mathrm{c}}(\mathbf{m} / \mathbf{s})$ \\
\hline Yerushalmi and Cankurt (1979) [27] & $\mathrm{U}_{\mathrm{c}}=3\left(\rho_{\mathrm{p}}{ }^{*} \mathrm{~d}_{\mathrm{p}}\right)^{0.5}-0.77$ & 0.32 \\
Lee and Kim (1988) [30] & $\operatorname{Re}_{\mathrm{c}}=0.7 \mathrm{Ar}^{0.485}$ & 1.00 \\
Leu, Huang and Gua (1990)[31] & $\operatorname{Re}_{\mathrm{c}}=0.568 \mathrm{Ar}^{0.578}$ & 1.60 \\
Horio (1991)[32] & $\operatorname{Re}_{\mathrm{c}}=0.936 \mathrm{Ar}^{0.472}$ & 1.46 \\
Bi and Grace (1995)[33] & $\operatorname{Re}_{\mathrm{c}}=0.565 \mathrm{Ar}^{0.461}$ & 0.83 \\
This work & & $\mathbf{0 . 8 2}$ \\
\hline
\end{tabular}

where $\rho_{\mathrm{p}}$ is particle density $\left(\mathrm{kg} / \mathrm{m}^{3}\right), \mathrm{d}_{\mathrm{p}}$ is particle diameter $(\mathrm{m})$ and $\mathrm{Ar}$ is Archimedes number $(-)$. 


\subsubsection{Transport velocity (Utr)}

The transition state from turbulent to fast fluidization regime is called transport velocity. The characteristic of this velocity can be defined as the minimum gas velocity which requires to carry over a significant number of particles discharged from the riser. Various approaches used to investigate transport velocity of solid particles in the fluidized bed such as flooding point velocity determination $[34,35]$, pressure drop calculating as a function of solids circulation rate and superficial gas velocities at the bottom of the column [3] and the emptying-times measurement technique of a fast fluidization column [36, 37]. Among these approaches, the emptying-times is the most interesting technique because this method is simple and convenient. Therefore, the empty-time was used to determine the transport velocity in this study.

In order to investigate the time-required, corresponding to all solids entrainment in the riser, no fresh solid feeding required into the column. The initial solid contents were placed constantly with 60 grams of samples. The results from Fig. 4 showed that there was no significant particle floated from the riser at low superficial gas velocities. On the other hand, when increasing the gas velocities, the solid particles could be transferred out from the riser. The transport velocity was taken to be the intersection of the lines of low and high accelerations and was found to be $2.22 \mathrm{~m} / \mathrm{s}$. The correlations for transport velocity as shown in Table 4 were developed by several literatures. Furthermore, the transport velocity obtained in this study was also compared with those calculated from available correlations.

Since the hydrodynamics characteristics of the circulating-turbulent fluidized bed or C-TFB regime velocity should be occurred between $u_{c}$ and $u_{t r}$, the inlet gas velocity for C-TFB would be between $0.82 \mathrm{~m} / \mathrm{s}$ to $2.22 \mathrm{~m} / \mathrm{s}$. The $\mathrm{u}_{\mathrm{c}}$ and $\mathrm{u}_{\mathrm{tr}}$ led to required experimental conditions in terms of the gas velocity. The obtained $\mathrm{u}_{\mathrm{c}}$ and $\mathrm{u}_{\mathrm{tr}}$ values of 0.82 and $2.22 \mathrm{~m} / \mathrm{s}$, respectively, were broadly equivalent to those reported previously of 1.02 and $2.34 \mathrm{~m} / \mathrm{s}$, respectively, [22].

Table 4. Comparison between transport velocity from correlations and velocity determined in this research

\begin{tabular}{lll}
\hline References & Correlations of $\mathrm{u}_{\mathrm{tr}}$ & $\mathrm{u}_{\mathrm{tr}}(\mathrm{m} / \mathrm{s})$ \\
\hline Parales et al. (1992) [36] & $\operatorname{Re}_{\mathrm{tr}}=1.41 \mathrm{Ar}^{0.483}$ & 2.36 \\
Bi and Fan (1992) [37] & $\operatorname{Re}_{\mathrm{tr}}=2.28 \mathrm{Ar}^{0.356}$ & 2.66 \\
Lee and Kim (1990b) [38] & $\operatorname{Re}_{\mathrm{tr}}=2.916 \mathrm{Ar}^{0.354}$ & 2.37 \\
Adanez et al. (1993) [28] & $\operatorname{Re}_{\mathrm{tr}}=2.08 \mathrm{Ar}^{0.458}$ & 3.01 \\
Chehbouni et al. (1994) [36] & $\operatorname{Re}_{\mathrm{tr}}=0.169 \mathrm{Ar}^{0.545}\left(\mathrm{D}_{\mathrm{t}} / \mathrm{d}_{\mathrm{p}}\right)$ & 1.13 \\
This work & & $\mathbf{2 . 2 2}$ \\
\hline
\end{tabular}

where $\mathrm{Ar}$ is Archimedes number (-), $\mathrm{D}_{\mathrm{t}}$ is reactor diameter and $\mathrm{d}_{\mathrm{p}}$ is particle diameter $(\mathrm{m})$.

\subsubsection{Time-average solid volume fraction in circulating-turbulent fluidized bed (C-TFB)}

To further understand C-TFB hydrodynamic behaviors, the flow pattern characterization of C-TFB was evaluated by measuring solid volume fraction $(\varepsilon)$. Solid volume fraction analysis in this study could be done by collecting the instantaneous pressure drop along the riser in the axial direction. To distinguish flow patterns/regimes, the calculation of solid volume fraction was determined by using differential pressures, $\Delta \mathrm{P}$, along the axial direction of the riser. A two-detector setup aligned at $0.1 \mathrm{~m}$ apart was used to detect particle in the riser. The relationship between $\Delta \mathrm{P}$ and $\varepsilon$ is shown in the Eq. (10) as follows:

$$
\Delta P=\rho_{s} g \varepsilon_{s} H
$$

which $\rho_{s}$ is the solid density $\left(\mathrm{kg} / \mathrm{m}^{3}\right)$, $\mathrm{g}$ is the gravity acceleration $\left(\mathrm{m} / \mathrm{s}^{2}\right), \varepsilon$ is the solid volume fraction (-) and $\mathrm{H}$ is the distance between two pressure sensors (m), respectively. 


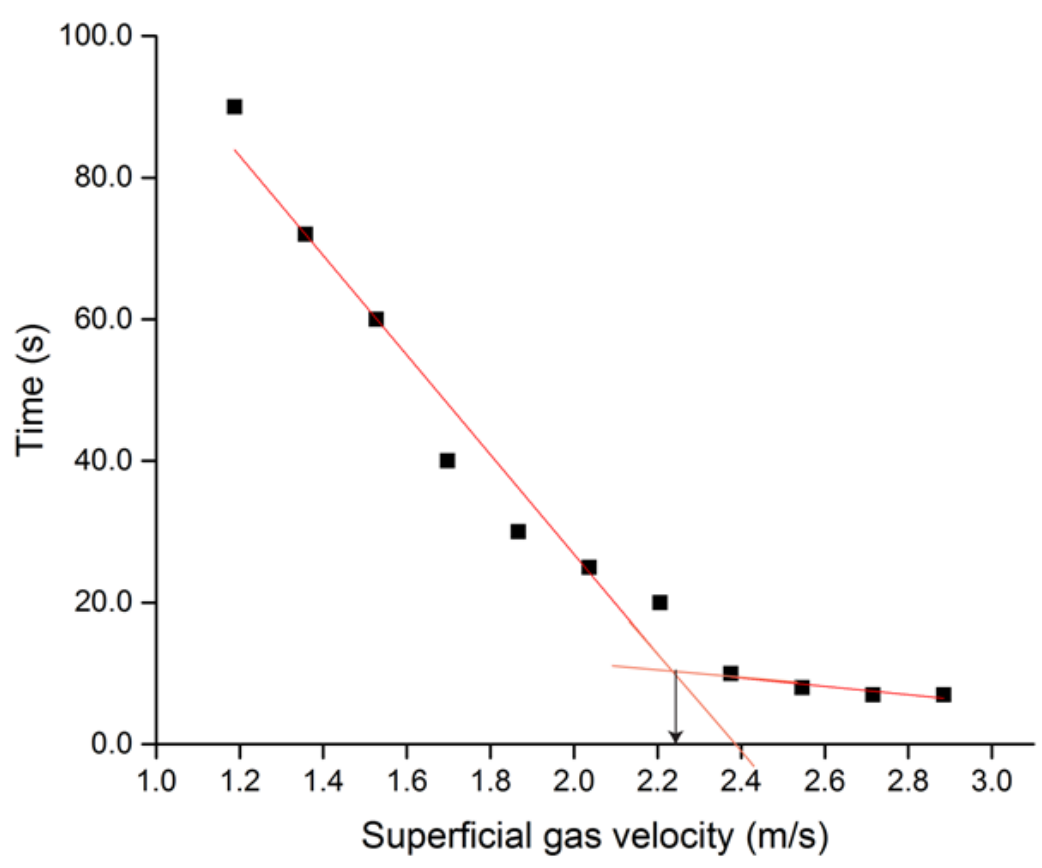

Fig. 4. Emptying-time of solid used in this study at various superficial gas velocities for solid loading of 60 grams.

Figure 5 shows solid volume fractions with various fluidization regimes. Comparing with the conventional regimes, solid volume fractions profiles of the fluidization regimes along the height of the riser in the axial direction, such as, turbulent fluidization, circulating turbulent fluidization and fast fluidization regimes, the conventional regimes provided solid volume fraction profiles of the fluidization regimes corresponding with Kunii and Levenspiel's book [38]. When increasing the superficial gas velocity to reach transition velocity $\left(\mathrm{u}_{\mathrm{c}}\right)$, the solid volume fraction in the riser showed separate regions of dense region at the bottom and dilute region at the top of the bed which could be described as a flow behavior of the turbulent fluidization regime. Due to solid particle in the bed could be easily distributed by gas in the turbulent fluidization regime, the solid volume fraction at the bottom was low. Therefore, the solid volume fraction profile along the height of the turbulent regime was gradually decreased along the height. To distinguish CTFB regime, at a superficial gas velocity of $1.00 \mathrm{~m} / \mathrm{s}$, it could be seen that solid volume profile at the bottom of the bed was relatively similar to the turbulent fluidization regime. However, an existing of the dense region also occurred at the top of the bed. A uniform distribution of solid volume fraction along the riser could imply the unique behavior of C-TFB regime, which was consistent with the discoveries of Zhu and Zhu [19] and Chalermsinsuwan et al [22]. In this study, the averaged solid volume fraction along an axial crosssectional area was 0.15 . For the fast fluidization regime or at a superficial gas velocity of $2.22 \mathrm{~m} / \mathrm{s}$, the solid volume fraction profile became conventional S-shaped profile.

In summary, the axial solid volume fraction profiles of the circulating-turbulent fluidized bed regimes could be obtained at superficial gas velocity of $1.00 \mathrm{~m} / \mathrm{s}$. This operating condition will be applied to study further in the single-cycle $\mathrm{CO}_{2}$ adsorption using $\mathrm{K}_{2} \mathrm{CO}_{3} / \mathrm{Al}_{2} \mathrm{O}_{3}$ solid sorbent. 


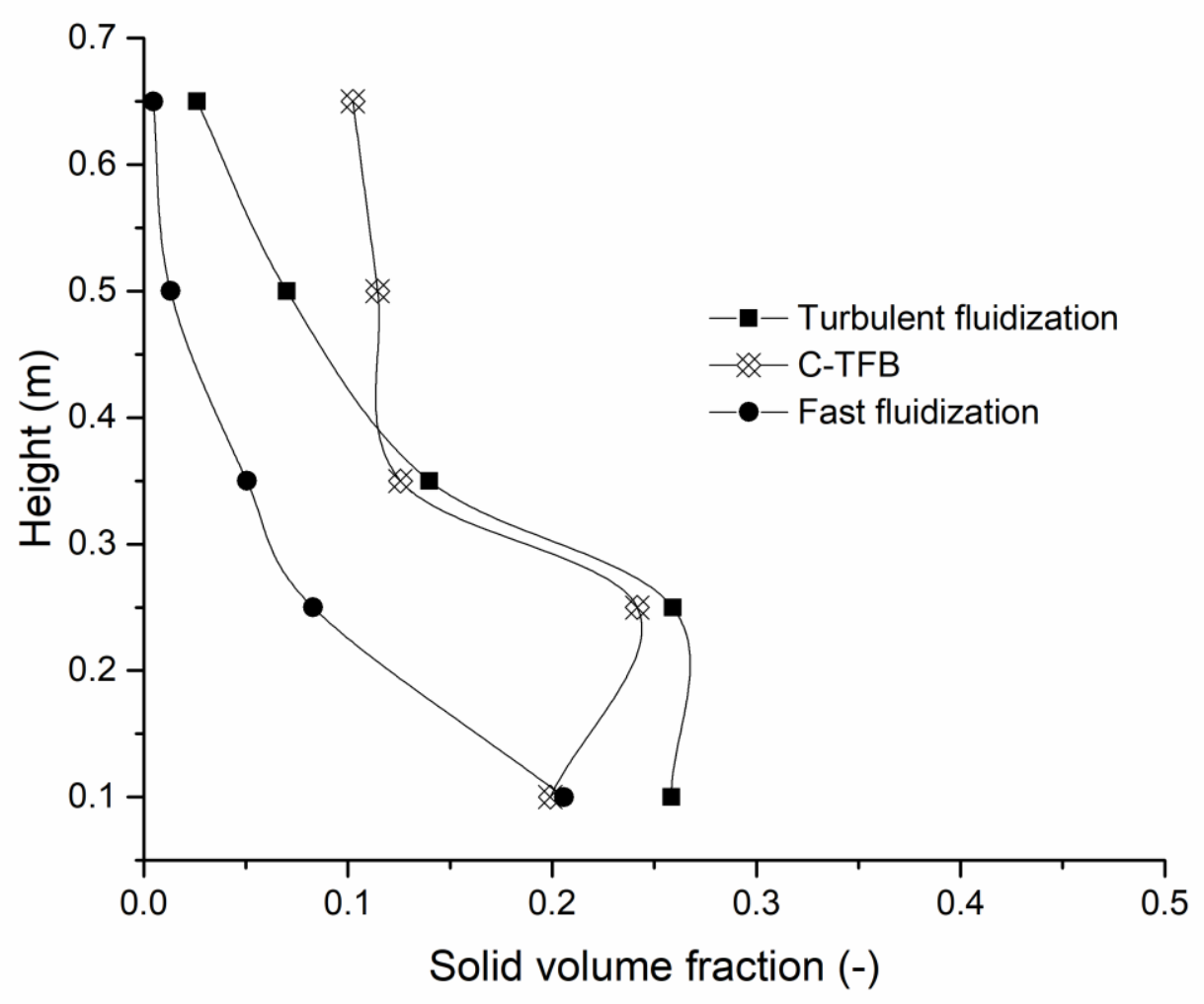

Fig. 5. Solid volume fraction profiles along the height of the riser at different superficial gas velocities $\left(\mathrm{U}_{\mathrm{g}}\right)$.

\section{2. $\mathrm{CO}_{2}$ Adsorption}

After obtaining the condition for operating the system under the C-TFB regime, the $\mathrm{CO}_{2}$ adsorption was studied in this regime. In this study, the experiments were performed at $60^{\circ} \mathrm{C}$ by using simulated flue gas with $\mathrm{CO}_{2}$ concentration of $12 \% \mathrm{vol}$ dry basis. The effect of water contents in feed gas in fluidized bed reactor was previously investigated by Jaiboon et al. [25], the results showed that the appropriate water content for $\mathrm{CO}_{2}$ adsorption is related to the $\mathrm{CO}_{2}$ concentration in flue gas inlet due to the stoichiometry as shown in Eq. (2). So, this study will use $18.4 \%$ vol. of water content in the feed gas. Figure 6 shows the effect of $\mathrm{CO}_{2}$ adsorption on flow patterns/regimes and $\mathrm{CO}_{2}$ capture capacity using $\mathrm{K}_{2} \mathrm{CO}_{3} / \gamma-\mathrm{Al}_{2} \mathrm{O}_{3}$ solid sorbent. Flow patterns/regimes in this study consisted of turbulent, C-TFB and fast fluidization regimes. At the reaction temperature, $\mathrm{CO}_{2}$ breakthrough curve of C-TFB showed the available $\mathrm{CO}_{2}$ in the feed gas at the beginning of time became zero, then the value increased with the reaction time increased. However, after the inlet velocity was increased to turbulent fluidization and fast fluidization regimes, the $\mathrm{CO}_{2}$ breakthrough curve could not be obtained visibly adsorbed all the $\mathrm{CO}_{2}$ concentration even at the beginning of time.

Considering the characteristic flow in C-TFB regime, the operation provided the highest $\mathrm{CO}_{2}$ adsorption for 4 minutes. The $\mathrm{CO}_{2}$ concentration at the outlet maintained at zero from the initial time up-to 4 minutes. Then the $\mathrm{CO}_{2}$ outlet concentration gradually increased and reached initial concentration. This is due to the characteristic of C-TFB which solid sorbent can be returned at the bottom of the riser. In this regime, 500 grams of solid sorbent was used to provide a sufficient time to complete cycle for determining the $\mathrm{CO}_{2}$ capture capacity. For turbulent and fast fluidization regimes, the breakthrough curves showed that the solid sorbents were unable to adsorb all available $\mathrm{CO}_{2}$ in the feed gas even at the beginning of the experiment. Since the increase of gas velocities causing the gas residence time in the riser to be shorter than others, as a result, the contacting time between gas-solid was inadequate to adsorb all available $\mathrm{CO}_{2}$. For the adsorption behavior under fast fluidization, the breakthrough curve showed about $75 \%$ of $\mathrm{CO}_{2}$ capture capacity at the beginning with the fresh solid loading. The operation was carried out by passing solid sorbent through the 
riser where the adsorption took place, then flowing to the other column as shown in Fig. 1 and returning to the bottom of the riser for next round of the adsorption. The recirculation of the sorbent was continued until the $\mathrm{CO}_{2}$ outlet concentration from the riser was equal to the initial concentration. As comparison with other regimes, fast fluidization showed poor adsorption behavior since the beginning of the operation. This is due to the contacting time between solid sorbent and gas was too short resulting in solid sorbent had inadequate time to completely react with all available $\mathrm{CO}_{2}$ in the flue gas.

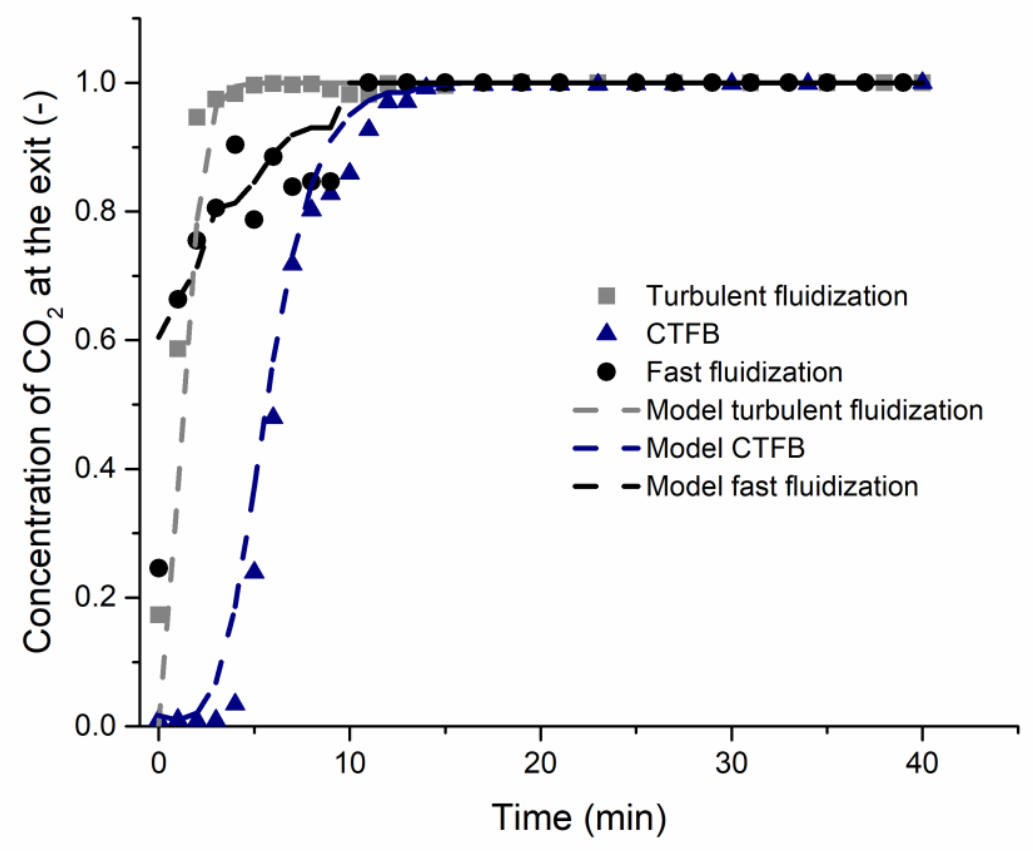

Fig. 6. Effect of adsorption on $\mathrm{CO}_{2}$ removal fraction at different regimes at different flow patterns/regimes

Figure 7 displayed the $\mathrm{CO}_{2}$ capture capacity of $\mathrm{K}_{2} \mathrm{CO}_{3} / \mathrm{Al}_{2} \mathrm{O}_{3}$ solid sorbent at different flow patterns/regimes. The results from the experiments revealed that the behavior of turbulent fluidization regime showed that the bubble phase vanished, owing to the rapid bubble coalescence and break-up. The gas velocity carried the amount of solid sorbent out of the expanded bed into the freeboard region. This can be implied that turbulent fluidization regime provides more interaction opportunity between gas and solid sorbent to react and get more $\mathrm{CO}_{2}$ adsorbed. For CTFB and fast fluidization regimes, the solid sorbent passed through the riser, moved out the riser into the other column for collecting coarse particles, then returned to the bottom of the riser as cycles. In these regimes 500 grams of solid sorbent was used to provide a sufficient time for completing a cycle and to determine the $\mathrm{CO}_{2}$ capture capacity. The amount of $\mathrm{CO}_{2}$ capture capacity of C-TFB regime in this experiment was approximately $215 \mathrm{mg} \mathrm{CO} / \mathrm{g}$ of $\mathrm{K}_{2} \mathrm{CO}_{3}$. It was $70 \%$ of theoretical value which was about $322 \mathrm{mg} \mathrm{CO} / \mathrm{g}$ of $\mathrm{K}_{2} \mathrm{CO}_{3}$. The investigation of the used solid sorbent will be explored further. The process which is capable for regenerating solid sorbent are temperature and depressurize. After adsorbed $\mathrm{CO}_{2}$ are released, the solid sorbent will be used to retest the $\mathrm{CO}_{2}$ adsorption performance. 


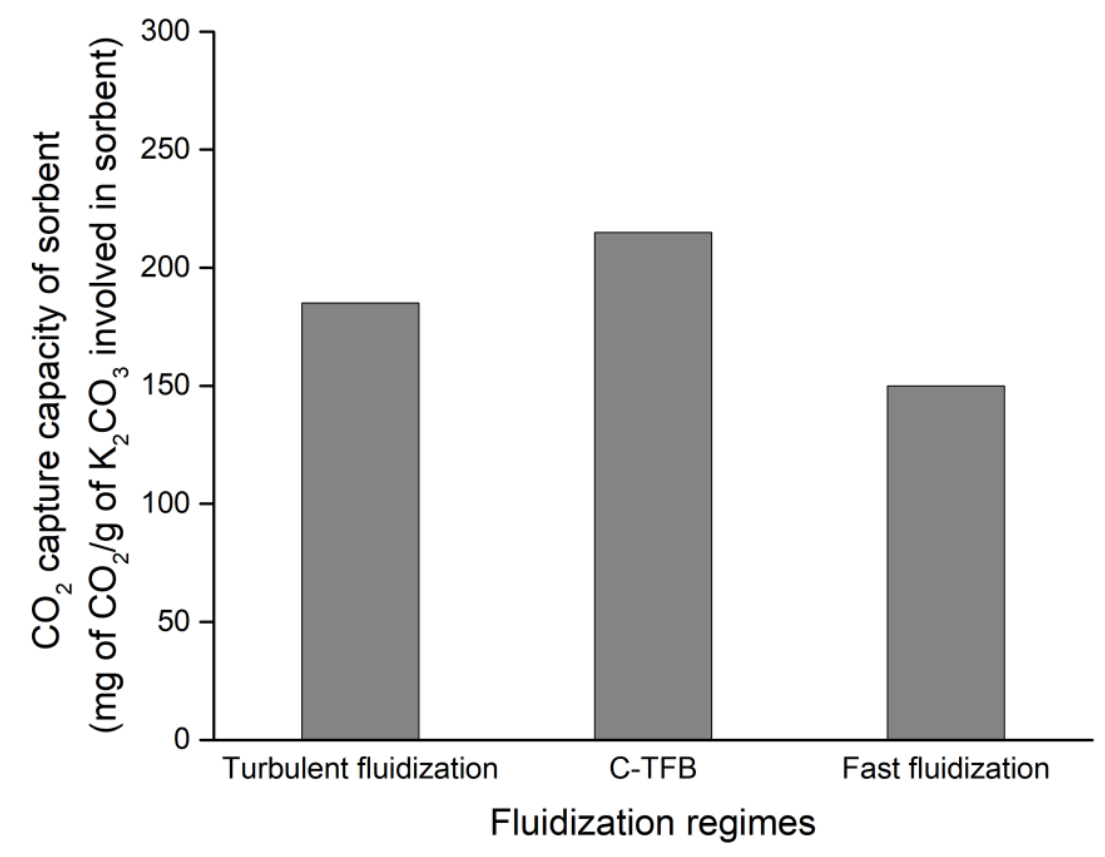

Fig. 7. Maximum $\mathrm{CO}_{2}$ capture capacity of $\mathrm{K}_{2} \mathrm{CO}_{3} / \mathrm{Al}_{2} \mathrm{O}_{3}$ solid sorbent at different flow regimes.

\subsection{Evaluation Kinetic Parameters}

Table 5 shows the corresponding kinetic parameters of $\mathrm{CO}_{2}$ sorption among different flow patterns/regimes. The $\mathrm{k}_{0}$ parameters were highest and lowest in C-TFB and fast fluidization regimes corresponding with the $\mathrm{CO}_{2}$ capture results, respectively. The calculation of the deactivation model and experimental breakthrough curves were consistent with each other as can be seen in Fig. 6. However, there was some deviation results at fast fluidization regimes due to the model limitation. The deactivation model was developed based on the plug flow model. Therefore, the system with homogeneous dense zone will be more fit with the data. At the beginning of sorption time, the $\mathrm{CO}_{2}$ breakthrough curves showed a maximum removal fraction and then the removal decreased when the reaction time moved on. In addition, the turbulent fluidization regime acquired the highest deactivation rate, $\mathrm{k}_{\mathrm{d}}$, while the fast fluidization regime obtained the lowest deactivation rate, $\mathrm{k}_{\mathrm{d}}$. The low deactivation model was observed in fast fluidization regime because the low $\mathrm{CO}_{2}$ capture.

Table 5. Effect of different flow regimes on breakthrough curves of outlet $\mathrm{CO}_{2}$ fraction and their corresponding kinetic parameters with $\mathrm{m}=1, \mathrm{n}=1$ and $18.4 \mathrm{vol} \%$. water content).

\begin{tabular}{|c|c|c|c|}
\hline Fluidization regime & $\begin{array}{l}\mathrm{k}_{0} \\
\text { (dimensionless) }\end{array}$ & $\begin{array}{l}\mathrm{k}_{\mathrm{d}} \\
\left(\mathrm{m}^{3} / \mathrm{kmol} \cdot \mathrm{s}\right)\end{array}$ & $\mathbf{R}^{2}$ \\
\hline Turbulent & 1.58 & 3.84 & 0.96 \\
\hline C-TFB & 3.63 & 0.86 & 0.98 \\
\hline Fast & 0.51 & 0.25 & 0.72 \\
\hline
\end{tabular}

\section{Conclusions}

The purpose of this study was to investigate the carbon dioxide capture process using solid sorbent method in a circulating fluidized bed reactor. From previous research work, it was found that the hydrodynamics under circulating turbulent fluidized bed (C-TFB) regime could promote the solid sorbent for $\mathrm{CO}_{2}$ capture process. The solid sorbent being used in this study was potassium carbonate on gamma type alumina supporter. The study started with finding the operating condition in the riser so that the particles flow in the 
reactor fell in the circulating turbulent fluidization regime. The experiment showed that when the gas velocity was $1.00 \mathrm{~m} / \mathrm{s}$, the CTFB regime took place and it was confirmed by the uniform distribution of solid volume fraction along the riser by pressure drop calculation. The solid volume fraction in the axial direction was 0.15 . For $\mathrm{CO}_{2}$ capture, in addition, the kinetic of the adsorption under various operating flow regimes in the riser was studied and the kinetic parameters corresponding to each regime were determined using deactivation kinetic model. The $\mathrm{k}_{0}$ parameters were highest and lowest in C-TFB and fast fluidization regimes corresponding with the $\mathrm{CO}_{2}$ capture results, respectively. In addition, the turbulent fluidization regime acquired the highest deactivation rate, $\mathrm{k}_{\mathrm{d}}$, while the fast fluidization regime obtained the lowest deactivation rate, $\mathrm{k}_{\mathrm{d}}$.

\section{Acknowledgement}

This research is supported by Rachadapisek Sompote Fund for Postdoctoral Fellowship, Chulalongkorn University and the Thailand Research Fund (RSA5980052).

\section{References}

[1] I. ETSAP, “CO 2 Capture and Storage,” IEA ETSAP-Technology Brief E14, 2010.

[2] M. Onischak and D. Gidaspow, "Separation of gaseous mixtures by regenerative sorption on porous solids: Part II. Regenerative separation of $\mathrm{CO}_{2}$," Recent Developments in Separation Science, vol. 2, pp. 72-93, 1972.

[3] S. Kongkitisupchai and D. Gidaspow, "Carbon dioxide capture using solid sorbents in a fluidized bed with reduced pressure regeneration in a downer," AIChE Journal, vol. 59, no. 12, pp. 4519-4537, 2013.

[4] Y. Liang, D. Harrison, R. Gupta, D. Green, and W. McMichael, "Carbon dioxide capture using dry sodium-based sorbents," Energy \& Fuels, vol. 18, no. 2, pp. 569-575, 2004.

[5] C. K. Ryu, "Development of $\mathrm{Na}$ and $\mathrm{K}$-based sorbents for $\mathrm{CO}_{2}$ capture from flue gas," in 4th Annual Conference on Carbon Capture and Sequestration, Washington, DC, USA, 2005.

[6] C. Zhao, X. Chen, C. Zhao, and Y. Liu, "Carbonation and hydration characteristics of dry potassiumbased sorbents for $\mathrm{CO}_{2}$ capture," Energy \& Fuels, vol. 23, no. 3, pp. 1766-1769, 2009.

[7] C. Zhao, X. Chen, and C. Zhao, " $\mathrm{CO}_{2}$ absorption using dry potassium-based sorbents with different supports," Energy \& Fuels, vol. 23, no. 9, pp. 4683-4687, 2009.

[8] S. C. Lee and J. C. Kim, "Dry potassium-based sorbents for $\mathrm{CO}_{2}$ capture," Catalysis Surveys from Asia, vol. 11, no. 4, pp. 171-185, 2007.

[9] S. C. Lee, B. Y. Choi, C. K. Ryu, Y. S. Ahn, T. J. Lee, and J. C. Kim, "The effect of water on the activation and the $\mathrm{CO}_{2}$ capture capacities of alkali metal-based sorbents," Korean Journal of Chemical Engineering, vol. 23, no. 3, pp. 374-379, 2006.

[10] S. C. Lee, Y. M. Kwon, C. Y. Ryu, H. J. Chae, D. Ragupathy, S. Y. Jung, J. B. Lee, C. K. Ryu, and J. C. Kim, "Development of new alumina-modified sorbents for $\mathrm{CO}_{2}$ sorption and regeneration at temperatures below 200C," Fuel, vol. 90, no. 4, pp. 1465-1470, 2011.

[11] C.-K. Yi, S.-H. Jo, Y. Seo, J.-B. Lee, and C.-K. Ryu, "Continuous operation of the potassium-based dry sorbent $\mathrm{CO}_{2}$ capture process with two fluidized-bed reactors," International Journal of Greenhouse Gas Control, vol. 1, no. 1, pp. 31-36, 2007.

[12] P. Khongprom and D. Gidaspow, "Compact fluidized bed sorber for $\mathrm{CO}_{2}$ capture," Particuology, vol. 8, no. 6, pp. 531-535, 2010.

[13] D. Gidaspow and M. Onischak, "Process for regenerative sorption of CO \{HD 2," U.S. Patent 3,865,924, Feb. 11, 1975.

[14] L. Li, X. Wen, X. Fu, F. Wang, N. Zhao, F. Xiao, W. Wei, and Y. Sun, "MgO/ $\mathrm{Al}_{2} \mathrm{O}_{3}$ sorbent for $\mathrm{CO}_{2}$ capture," Energy \& Fuels, vol. 24, no. 10, pp. 5773-5780, 2010.

[15] J. C. Abanades, E. J. Anthony, J. Wang, and J. E. Oakey, "Fluidized bed combustion systems integrating $\mathrm{CO}_{2}$ capture with CaO,” Environmental Science \& Technology, vol. 39, no. 8, pp. 2861-2866, 2005.

[16] B. Chalermsinsuwan, P. Piumsomboon, and D. Gidaspow, "A computational fluid dynamics design of a carbon dioxide sorption circulating fluidized bed," AIChE Journal, vol. 56, no. 11, pp. 2805-2824, 2010.

[17] Y. C. Park, S.-H. Jo, K.-W. Park, Y. S. Park, and C.-K. Yi, "Effect of bed height on the carbon dioxide capture by carbonation/regeneration cyclic operations using dry potassium-based sorbents," Korean Journal of Chemical Engineering, vol. 26, no. 3, pp. 874-878, 2009. 
[18] S. C. Lee, B. Y. Choi, T. J. Lee, C. K. Ryu, Y. S. Ahn, and J. C. Kim, " $\mathrm{CO}_{2}$ absorption and regeneration of alkali metal-based solid sorbents," Catalysis Today, vol. 111, no. 3, pp. 385-390, 2006.

[19] H. Zhu and J. Zhu, "Gas- solids flow structures in a novel circulating- turbulent fluidized bed," AIChE journal, vol. 54, no. 5, pp. 1213-1223, 2008.

[20] H. Zhu and J. Zhu, "Comparative study of flow structures in a circulating-turbulent fluidized bed," Chemical Engineering Science, vol. 63, no. 11, pp. 2920-2927, 2008.

[21] J. Parssinen and J. Zhu, "Axial and radial solids distribution in a long and high-flux CFB riser," American Institute of Chemical Engineers. AIChE Journal, vol. 47, no. 10, p. 2197, 2001.

[22] B. Chalermsinsuwan, D. Gidaspow, and P. Piumsomboon, "In-depth system parameters of transition flow pattern between turbulent and fast fluidization regimes in high solid particle density circulating fluidized bed reactor," Powder Technology, vol. 253, pp. 522-536, 2014.

[23] O. Levenspiel, "Chemical reaction engineering," Industrial \& Engineering Chemistry Research, vol. 38, no. 11, pp. 4140-4143, 1999.

[24] D. K. Lee, D. Y. Min, H. Seo, N. Y. Kang, W. C. Choi, and Y. K. Park, "Kinetic Expression for the Carbonation Reaction of $\mathrm{K}_{2} \mathrm{CO}_{3} / \mathrm{ZrO}_{2}$ Sorbent for $\mathrm{CO}_{2}$ Capture," Industrial \& Engineering Chemistry Research, vol. 52, no. 26, pp. 9323-9329, 2013.

[25] O.-A. Jaiboon, B. Chalermsinsuwan, L. Mekasut, and P. Piumsomboon, "Effect of flow patterns/regimes on $\mathrm{CO}_{2}$ capture using $\mathrm{K}_{2} \mathrm{CO}_{3}$ solid sorbent in fluidized bed/circulating fluidized bed," Chemical engineering journal, vol. 219, pp. 262-272, 2013.

[26] Y. Seo, S.-H. Jo, H.-J. Ryu, H. Dal Bae, C. K. Ryu, and C.-K. Yi, "Effect of water pretreatment on $\mathrm{CO}_{2}$ capture using a potassium-based solid sorbent in a bubbling fluidized bed reactor," Korean Journal of Chemical Engineering, vol. 24, no. 3, pp. 457-460, 2007.

[27] J. Yerushalmi and N. Cankurt, "Further studies of the regimes of fluidization," Powder Technology, vol. 24, no. 2, pp. 187-205, 1979.

[28] V. Jiradilok, D. Gidaspow, S. Damronglerd, W. J. Koves, and R. Mostofi, "Kinetic theory based CFD simulation of turbulent fluidization of FCC particles in a riser," Chemical Engineering Science, vol. 61, no. 17, pp. 5544-5559, 2006.

[29] J. R. Grace, T. Knowlton, and A. Avidan, Circulating Fluidized Beds. Springer Science \& Business Media, 2012.

[30] G. S. Lee and S. D. Kim, "Pressure fluctuations in turbulent fluidized beds," Journal of Chemical Engineering of Japan, vol. 21, no. 5, pp. 515-521, 1988.

[31] L. P. Leu, J. W. Huang, and B. B. Gua, "Axial pressure distribution in turbulent fluidized beds," in Proceedings of the Second Asian Conference on Fluidized-Bed and Three-Phase Reactor, 1990, pp. 71-79.

[32] M. Horio, "Hydrodynamics of circulating fluidization-Present status and research needs," Circulating Fluidired Bed Technology III, pp. 3-14, 1991.

[33] H. Bi and J. Grace, "Effect of measurement method on the velocities used to demarcate the onset of turbulent fluidization," The Chemical Engineering Journal and the Biochemical Engineering Journal, vol. 57, no. 3, pp. 261-271, 1995.

[34] H. Luo, H. Chioyama, S. Thürmer, T. Ohba, and H. Kanoh, "Kinetics and Structural Changes in $\mathrm{CO}_{2}$ Capture of $\mathrm{K}_{2} \mathrm{CO}_{3}$ under a Moist Condition," Energy \& Fuels, vol. 29, no. 7, pp. 4472-4478, 2015.

[35] J. Adanez, L. De Diego, and P. Gayan, "Transport velocities of coal and sand particles," Powder Technology, vol. 77, no. 1, pp. 61-68, 1993.

[36] A. Almuttahar and F. Taghipour, "Computational fluid dynamics of high density circulating fluidized bed riser: Study of modeling parameters," Powder Technology, vol. 185, no. 1, pp. 11-23, 2008.

[37] L. Huilin, H. Yurong, and D. Gidaspow, "Hydrodynamic modelling of binary mixture in a gas bubbling fluidized bed using the kinetic theory of granular flow," Chemical Engineering Science, vol. 58, no. 7, pp. 1197-1205, 2003.

[38] D. Kunii and O. Levenspiel, Fluidization Engineering. Elsevier, 2013. 